IZA DP No. 9573

Informal versus Formal Search:

Which Yields a Better Pay?

Semih Tumen

December 2015 


\title{
Informal versus Formal Search: Which Yields a Better Pay?
}

\author{
Semih Tumen \\ Central Bank of the Republic of Turkey \\ and IZA
}

Discussion Paper No. 9573

December 2015

\author{
IZA \\ P.O. Box 7240 \\ 53072 Bonn \\ Germany \\ Phone: +49-228-3894-0 \\ Fax: +49-228-3894-180 \\ E-mail: iza@iza.org
}

\begin{abstract}
Any opinions expressed here are those of the author(s) and not those of IZA. Research published in this series may include views on policy, but the institute itself takes no institutional policy positions. The IZA research network is committed to the IZA Guiding Principles of Research Integrity.

The Institute for the Study of Labor (IZA) in Bonn is a local and virtual international research center and a place of communication between science, politics and business. IZA is an independent nonprofit organization supported by Deutsche Post Foundation. The center is associated with the University of Bonn and offers a stimulating research environment through its international network, workshops and conferences, data service, project support, research visits and doctoral program. IZA engages in (i) original and internationally competitive research in all fields of labor economics, (ii) development of policy concepts, and (iii) dissemination of research results and concepts to the interested public.
\end{abstract}

IZA Discussion Papers often represent preliminary work and are circulated to encourage discussion. Citation of such a paper should account for its provisional character. A revised version may be available directly from the author. 


\section{ABSTRACT \\ Informal versus Formal Search: Which Yields a Better Pay?*}

Estimates on the effect of job contact method - i.e., informal versus formal search - on wage offers vary considerably across studies, with some of them finding a positive correlation between getting help from informal connections and obtaining high-paying jobs, while others finding a negative one. In this paper, I theoretically investigate the sources of discrepancies in these empirical results. Using a formal job search framework, I derive an equilibrium wage distribution which reveals that the informal search yields for some groups higher and for some others lower wages than formal search. The key result is the existence of nonmonotonicities in wage offers. Two potential sources of these nonmonotonicities exist: $(i)$ peer effects and (ii) unobserved worker heterogeneity in terms of the inherent cost of maintaining connections within a productive informal network. The model predicts that a greater degree of unobserved heterogeneity tilts the estimates toward producing a positive correlation between informal search and higher wages, whereas stronger peer influences tend to yield a negative correlation. This conclusion informs the empirical research in the sense that identification of the true correlation between job contact methods and wage offers requires a careful assessment of the unobserved heterogeneity and peer influences in the relevant sample.

JEL Classification: D85, J31, J64

Keywords: job search, informal networks, peer effects, heterogeneity, nonmonotonicities

Corresponding author:

Semih Tumen

Research and Monetary Policy Department

Central Bank of the Republic of Turkey

Istiklal Cad. No:10

06100 Ulus, Ankara

Turkey

E-mail: semih.tumen@tcmb.gov.tr

\footnotetext{
* I thank Patrick Doreian, Steve Durlauf, Luca Flabbi, James Heckman, Brent Hickman, Ayse Imrohoroglu, Rafael Lopes de Melo, William Neilson, seminar participants at the University of Bern, University of Chicago, and the participants of the 2012 European Society for Population Economics conference in Bern, and 2012 Econometric Society European Meeting in Malaga for their useful suggestions. I am particularly grateful to Makoto Yano (the editor) and an anonymous referee for very helpful comments. The views expressed here are of my own and do not necessarily reflect those of the Central Bank of the Republic of Turkey. All errors are mine.
} 


\section{Introduction}

What rationalizes the choice between using versus not using informal job search channels is not well understood in the literature. ${ }^{1}$ Neither is it often well-grounded why some groups rely more on these social contacts than others, nor why the patterns of wages vary across these groups. The well-known stylized fact that around a half of all new jobs are filled through social contacts in major developed economies throws the endeavor to investigate the connections between the choice of job search method and the associated labor market outcomes into sharp relief. ${ }^{2}$

In this paper, I pose the question "whether informal search methods generate higher or lower wage offers than formal search." There is a divide in the empirical literature, with some studies finding a positive correlation between getting help from informal connections and obtaining high-paying jobs, while others finding a negative one. ${ }^{3}$ I attempt to put together a coherent theoretical story that can shed some light on this puzzle. My purpose is to construct a theoretical model, using which one can practically disentangle the forces governing the correlation between job contact methods and wage outcomes. Such a framework will inform the empirical research about the potential avenues that can be followed in reconciling the contradictory findings reported in the existing literature.

Using a discrete choice model of job search with worker heterogeneity and segmented markets, I derive an equilibrium wage distribution which demonstrates that the jobs found through informal methods pay for some groups higher and for some others lower wages than the jobs found through formal methods. ${ }^{4}$ The key is the existence of nonmonotonicities in wage offers. The main choice of the unemployed job searcher is to decide whether to search informally

\footnotetext{
${ }^{1}$ Formal sources of job information are the publicly available hiring channels such as newspaper ads, employment agencies, union hiring services, and various other placement services. The informal sources include referrals from relatives, friends, acquaintances, and direct/indirect contacts through social networks.

${ }^{2}$ See, for example, Rees (1966), Corcoran, Datcher, and Duncan (1980), Holzer (1988), Marsden and Campbell (1990), Granovetter (1995), Bewley (1999), Addison and Portugal (2002), and Ioannides and Loury (2004).

${ }^{3}$ See Ioannides and Loury (2004) for an extensive review of the related literature.

${ }^{4}$ Workers differ in terms of the inherent cost of maintaining connections with a productive informal network. Using formal methods in job search is costless for all workers, whereas the cost of staying connected with an informal network is distributed around zero. In other words, some groups have inherent a priori advantages that provide incentives to invoke informal contacts, while others have disadvantages and are driven to rely on formal methods only. The following insight from Calvo-Armengol and Jackson (2004) motivates the source of worker heterogeneity: if there are costs associated with remaining in a network, those who have lower costs will be more willing to stay connected. The sources of these costs include skill maintenance, education, and various opportunity costs. Similar references to cost heterogeneity are also provided in various studies, including Holzer (1988) and Mortensen and Vishwanath (1994).
} 
and/or formally. Those who choose to search via formal methods only receive a certain equilibrium wage. Wages of those who choose to call their informal connections may be lower or higher than the wage offer generated through formal search. In particular, I show that, at the equilibrium, a certain fraction - say $L \in[0,1]$ - of informal searchers accept lower wages than the formal methods can generate and the remaining ones - say $H=1-L \in[0,1]$ - accept higher wages. The main theoretical insight of the paper is the following. The relative sizes of $L$ and $H$ are determined by two factors: unobserved heterogeneity in the cost of informal search and the degree of peer effects in the relevant population.

The first prediction of the model is that a greater degree of unobserved heterogeneity in the cost of informal search increases the likelihood of a positive correlation between using informal search and earning high wages. This suggests that as the fraction of better-connected workers increase in the population, informal search will be more likely to yield higher wages. Failing to control for this unobserved heterogeneity element may lead to contradictory estimates depending on which part of the population the sample represents. For example, Marmaros and Sacerdote (2002), a breakthrough paper in the literature, document a positive correlation between earnings and the tendency of using informal contacts; but their sample consists of Darthmouth College seniors, who are potentially much better connected than a sample representing the whole population in the United States. Simon and Warner (1992) also document a positive correlation using a sample of individuals from the 1972 Survey of Natural and Social Scientists and Engineers. This sample also potentially suffers from the same problem. Similarly, Rosenbaum, DeLuca, Miller, and Roy (1999) find that the correlation between earnings and getting help from "close relatives" tend to be positive as men aged from 19 to 28 years. This is again plagued with a similar problem, because one becomes better connected as his/her close relatives - i.e., cousins, brothers, sisters - get older and become better connected. Similar arguments also hold for the papers reporting a negative correlation. For example, Elliot (1999) documents that workers residing in some certain neighborhoods, who find jobs through nonwhite contacts, tend to receive low wage offers. Similarly, papers including Beggs and Hurlbert (1997), Mencken and Winfield (2000), and Smith (2000) argue 
that jobs found through uneducated female contacts systematically pay lower wages than the jobs found through formal methods. These papers tend to oversample individuals with poor connections. I conclude that failing to control for unobserved heterogeneity (characterizing if the worker is well-connected or not) may lead to misleading estimates of the sign of the correlation between informal contacts and earnings. ${ }^{5}$

The second potential source is social interactions (or peer effects). With peer effects, the individual worker's choice of the search method is affected from the choices of other workers in the reference group or neighborhood [Bayer, Ross, and Topa (2008)]. For example, an unemployed worker who wants to work at a large steel factory close to the neighborhood he/she lives would tend to invoke his/her contacts working in this factory if a significant portion of residents work in the same factory and if the norm is to search informally in the neighborhood. This kind of connection patterns are generally observed in poor neighborhoods, where most residents are blue-collar workers employed in a nearby factory. The model predicts that stronger peer influences increase the likelihood of a negative correlation between earnings and informal search. In other words, stronger peer effects make the workers at the lower end of the informal job seekers rely on referrals more intensively. Thus, peer effects operate among low wage earners. This result embodies another empirical suggestion: peer effects should also be controlled for in applied work, besides unobserved heterogeneity.

There is a theoretical literature aiming to understand the economic foundations of the relationship between earnings and job contact methods. But, just as the empirical literature, the theoretical results are also mixed. Early papers, including Saloner (1985) and Montgomery (1991), find that job search through informal contacts leads to a better exchange of information between the applicants and potential employers, thus it results in higher-quality matches and the pay is higher. As opposed to this view, Bentolila, Michelacci, and Suarez (2010) show that job search through informal connections may lead to inefficiencies as it may cause firms to hire workers quickly and solely based on subjective or premature referrals. ${ }^{6}$ Both of these

\footnotetext{
${ }^{5}$ There are also studies reporting zero correlation [see Bridges and Villemez (1986), Holzer (1987), and Marsden and Gorman (2001)], and both positive and negative correlations [see Antoninis (2006) and Pellizzari (2010)]. See Loury (2006) for an excellent discussion of the sampling problems affecting the estimates in this literature.

${ }^{6}$ Fontaine (2008) argues that one's informal network grows over the life cycle, which means that initial wage disadvantages
} 
views provide valuable insights into the problem under question. However, they fail to fully explain the sources of discrepancies in the empirical results. My model presents a unifying theoretical construct by bringing positive and negative correlations between wages and informal search together within a general equilibrium framework. The model is, therefore, capable of disentangling the forces governing the sign and the magnitude of the empirical correlation between earnings and informal connections.

In terms of the results, this paper is closest to Pellizzari (2010). Pellizzari builds a theoretical model to argue that using informal methods can either lead to a wage penalty or a wage premium. The model he develops is a simple three-period matching model, but the simplicity comes at a cost: unemployed workers accept all offers and wage determination is exogenous. This paper pushes the frontier in this literature in the sense that it extends Pellizzari's work into a version of the canonical Mortensen-Pissarides model, in which wages are endogenously determined in a general equilibrium setting and workers are allowed to reject any offer that they do not like. The main insights from the general equilibrium setting are that any factor affecting the unemployed workers' choices of searching formally versus informally also affects the wage distribution and, moreover, the strength of one's connections enters the Nash bargain in wage determination. This general equilibrium effects interact with the two factors I mention above, unobserved heterogeneity and peer influences, in determining the relative sizes of $L$ and $H$ in the economy, as well as which workers search informally and which ones search formally. I show that Pellizzari's main finding (that informal methods can either lead to a wage penalty or a wage premium) holds in this general equilibrium setting too. Such a setup allows me to derive sharp formulas for the distributions of equilibrium wages and unemployment rates. I analyze the sources of wage penalties or premia by performing intuitive comparative statics exercises.

In a more recent paper, Zaharieva (2012) also shows that positive and negative forces coexist in the determination of the effect of job contact methods on wages. Specifically, she shows

of search by informal contacts may be replaced with wage advantages as one gets older and accumulates more experience. This view predicts that the correlations may also vary over the life cycle. 
that referrals have a positive effect on reservation wages (because better connected workers can bargain higher wages), while there is also a negative effect due to negative selection (i.e., the average productivity of a referred worker tends to be lower than the average productivity at the market level). In a companion paper, Zaharieva (2013) demonstrates that wages are ex-post bargained and can deviate (in both directions) from the posted wage depending on the worker's bargaining power.

The plan of the paper is as follows. Section 2 sketches the main results and motivates the model. Section 3 presents the model and its solution. The model presented in Section 3 rules out peer influences for simplicity. Section 4 introduces peer effects and describes the effect of social forces on wage differentials. Section 5 concludes.

\section{Motivation and Sketch of the Results}

The key result is the existence of nonmonotonicities in wages. As explained above, the source of these nonmonotonicities is twofold: worker heterogeneity and peer influences. Heterogeneity comes from the differences across workers in terms of the inherent cost of maintaining connections with a productive informal network. This cost reflects how well-connected the workers are. Those who are well-connected have inherent advantages in informal search, whereas those who are not so well-connected will tend to rely on formal methods since the cost of accessing a productive network is high for them. Peer influences are related to social forces diffusing into individual-level decision making. Referrals and social interactions are the main forms of these influences. Below I discuss how the existence of cost heterogeneity and peer effects can be related to wage nonmonotonicities and how this relation can be associated with the results documented in the empirical literature.

Figure (2.1) exemplifies the nature of the equilibrium outcomes that I focus on in this paper. Workers differ in the cost of using informal contacts in job search and the cost of using formal methods are the same for all workers. More precisely, the cost of using formal methods is set to zero for all workers and the cost of using informal contacts is assumed - for simplicity — to 


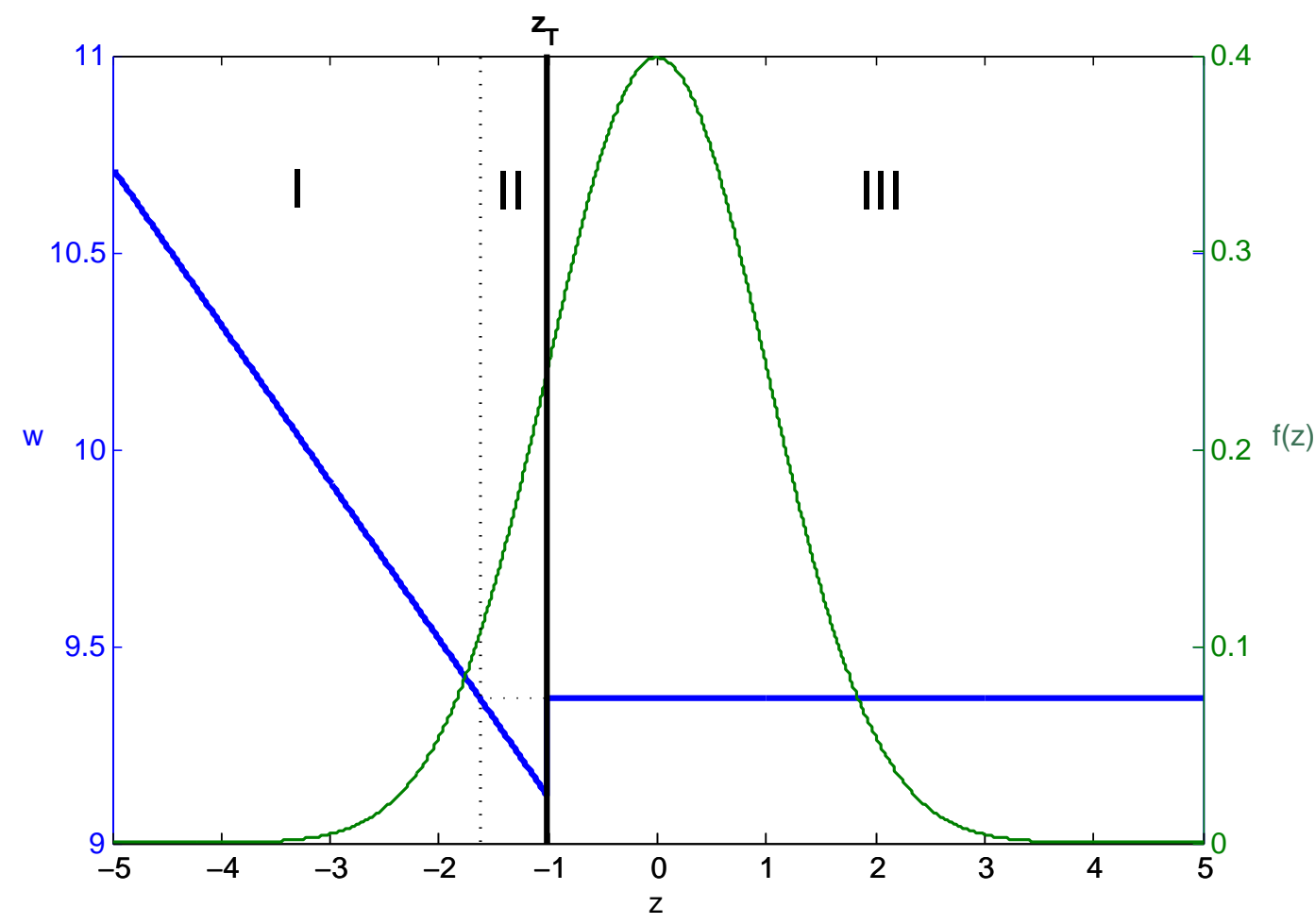

Figure 2.1: Wage Distribution and nonmonotonicities. This figure describes the distribution of wages and demonstrates the existence of nonmonotonicities in wages. The downward sloping portion of the wage schedule describes the wages that informal job seekers receive, whereas the horizontal portion describes formal job seekers' wages. Obviously, a fraction of the informal job seekers earn lower and the rest earn higher wages than formal job seekers. This is only an example and the underlying parameterization is given in Section 3.

be symmetrically distributed around zero. ${ }^{7}$ Nonmonotonicities in wages can be clearly seen in Figure (2.1). Worker types $z$-which define the individual-level heterogeneity in the cost of search via informal methods - are on the horizontal axis, wages $w(z)$ are on the left-vertical axis, and the probability density $f(z)$ of worker types is on the right-vertical axis. First, observe that, there exists an endogenous threshold type, $z_{T}$, below which workers invoke their informal contacts [Regions I \& II]. The ones with high cost of searching via informal contacts choose the formal methods, which yield a wage that is constant across types [Region III]. Comparison of the wages in Region III with those in Region I and Region II shows the

\footnotetext{
${ }^{7}$ To be concrete, I assume that $z$ is normally distributed with mean zero. Existence of a cost distribution can be justified as follows. It is argued in the literature that job search through informal networks are less costly and more productive. If this were the case, then all unemployed workers would use informal search ruling out the formal methods. But this is clearly not the case as there is a fair mix of formal and informal search across unemployed workers. Some papers, including Pistaferri (1999), argue that less-skilled workers prefer informal contacts more than skilled workers. But, again, this statement is only partially true, since it is well known that becoming top managers or finding jobs in top firms/institutions also require strong informal connections. For example, highly skilled workers tend to offer their skills directly to employers through their connections rather responding to publicly available opportunities [Heath (1999), Böheim and Taylor (2002)]. Evidently, it is hard to agree on a strict rule about whether it is in general less costly to search informally or whether workers of a specific skill category necessarily invokes social contacts more intensively. This suggests that, theoretically speaking, there is considerable (within- and between-group) heterogeneity in the relative cost of search via informal contacts and it is one of the determinants of who does what in terms of the method of job search.
} 


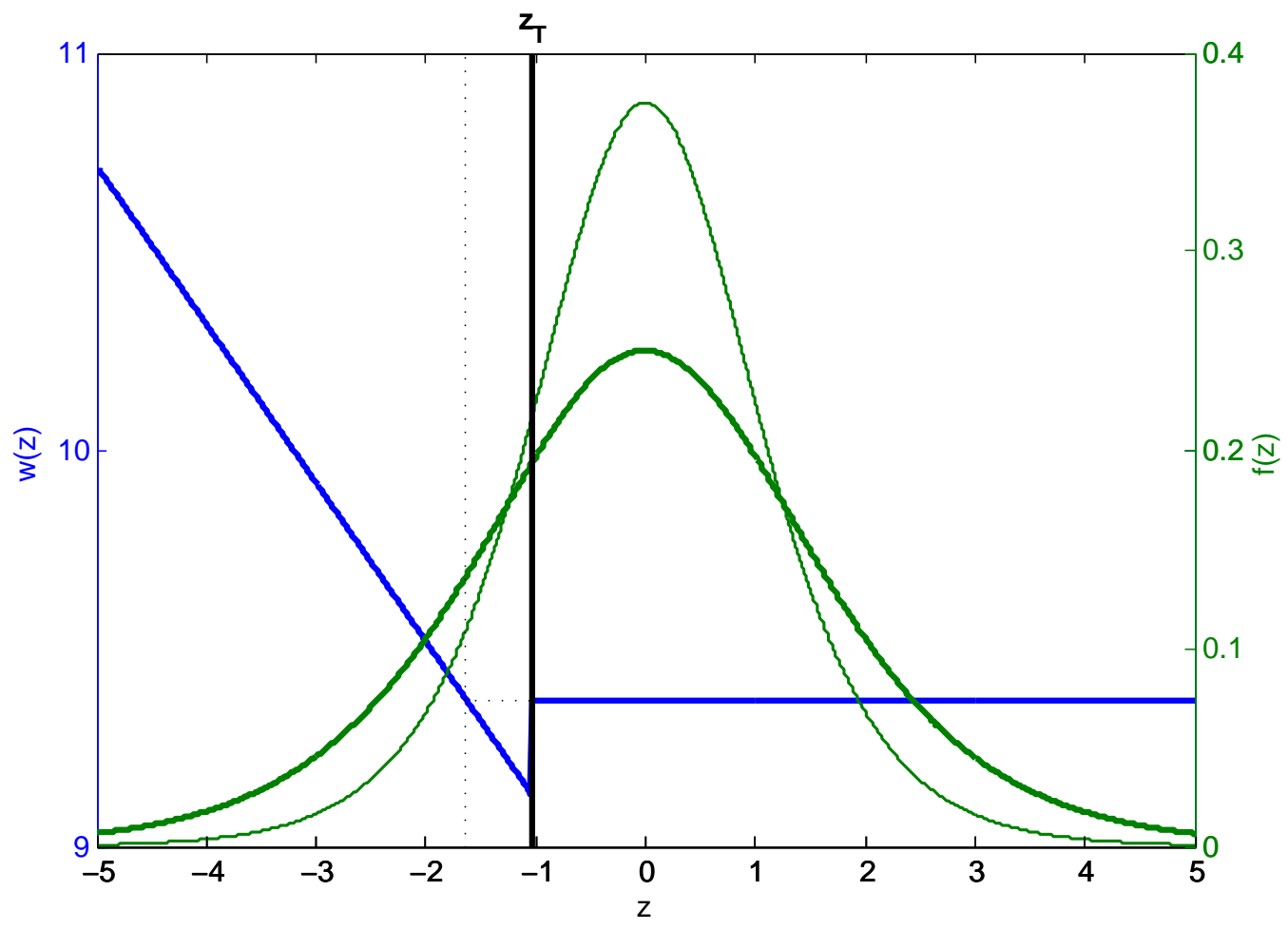

Figure 2.2: InCREASED HETEROGENEITY. This figure describes the effect of increased inequality in the distribution of the cost of informal search on wages. The extent of nonmonotonicities - and, thus, the threshold type - is unaltered in this case, but the wages are pushed out to tails. Clearly, with increased heterogeneity, the fraction of high wage earners among informal job seekers is larger. Peer effects are ruled out in this example.

nonmonotonicities in wages; that is, search via informal contacts results in for some groups higher pay and for some others lower pay than search via formal methods. Notice that the mass of workers in Region I corresponds to $H$ defined in Section 1 and the mass in Region II corresponds to $L$.

The underlying model is a version of the standard Mortensen-Pissarides framework with segmented markets and worker heterogeneity. Wages are determined via Nash bargaining in each sub-market. Informal search is more productive for all workers, although it is relatively more costly on the right-tail versus the left-tail of the type distribution. So, there is a cost-benefit tradeoff along this margin. That informal search is more productive (i.e., it yields a higher job finding rate) reduces the duration of unemployment for those who typically rely on informal methods. ${ }^{8}$ Those who have extremely low cost (i.e., the ones close to the left tail) can tolerate

\footnotetext{
${ }^{8}$ This assumption is empirically justified. The monthly Current Population Survey (CPS) data contain information about the job search methods of the unemployed. The data suggest that almost all of the unemployed workers (i.e., those actively seeking a job) in the US use formal job search methods, but only around 20 percent of them use "also" informal contacts in job search. This means that those relying on informal methods use formal and informal methods simultaneously. Moreover, the data suggest
} 


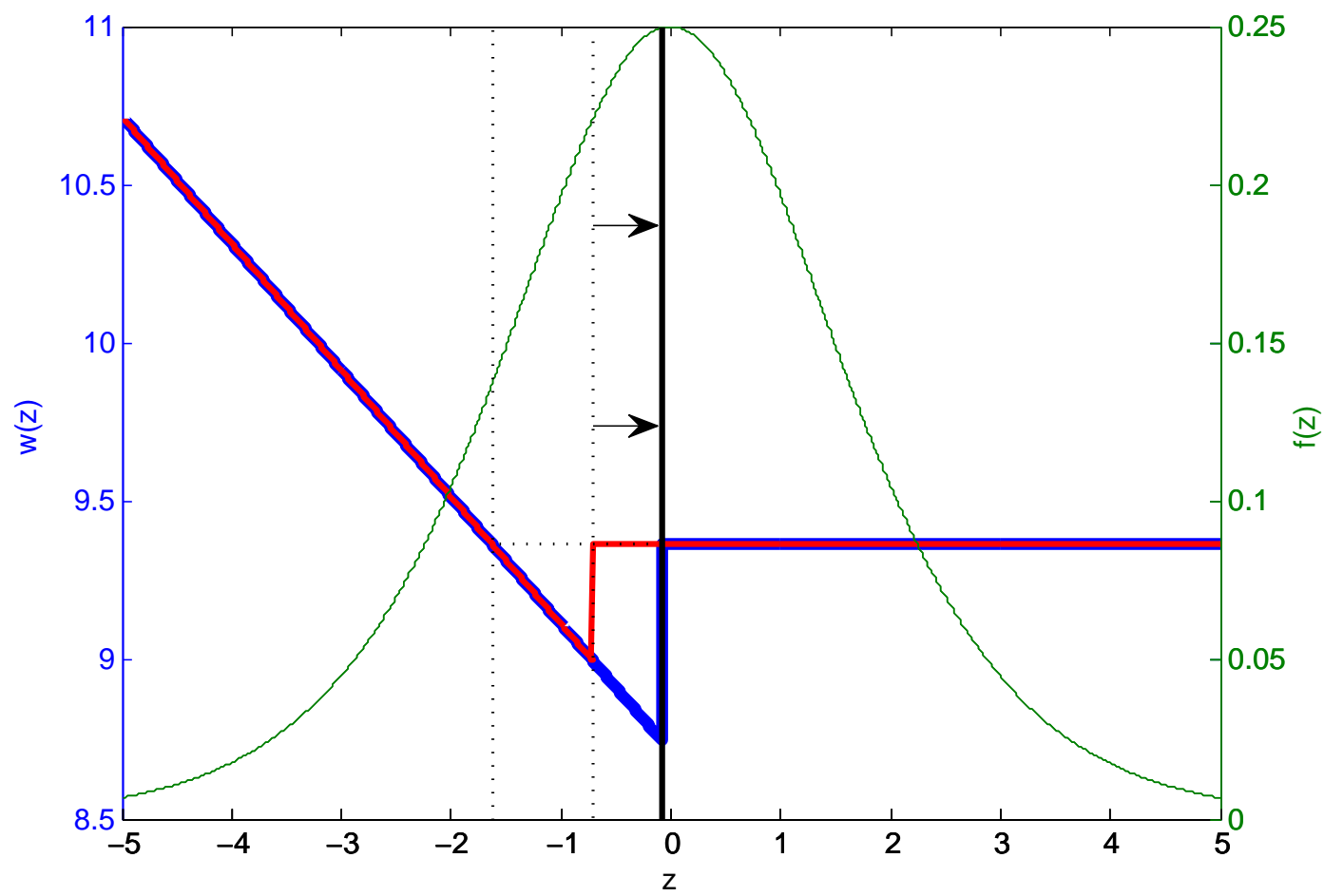

Figure 2.3: Stronger PEer Influences. This figure shows the effect of stronger peer influences on wages. The type distribution is unaltered. The red line corresponds to the wage function with weaker peer effects, while the blue line describes stronger peer effects. As the peer effects become stronger, the degree of nonmonotonicities gets larger. Notice that stronger peer effects raise the fraction of low-earners among the informal job seekers. The threshold type $z_{T}$ shifts to the right.

staying unemployed for a longer time, but firms in those markets will lose output if the job remains vacant that long. Thus, firms are willing to pay high wages for those workers. In other words, the strength of one's connections enters the Nash bargain. This explains Region I. In Region II, the expected duration of unemployment is low, but the workers' willingness to wait for the most desirable wage offer to arrive is not as high as the ones on the left tail. As a result, they compare the wages that they would get had they searched via formal methods and a lower paying job, in which they expect to stay unemployed for a shorter period of time. Firms know this, and they offer a lower wage in Region II. Region III resembles the textbook Mortensen-Pissarides wages. Notice that $z_{T}$ is endogenously determined within the model.

As I discuss in Section 1, there is no consensus about the effect of informal search on wages in the empirical literature. Some papers find a positive correlation between informal search and

that the job finding rate is slightly higher - therefore, the unemployment duration is slightly lower-for the unemployed workers who use both formal and informal methods in job search relative to those who rely only on formal methods. Note that these patterns, as the result of this paper suggests, do not imply that those using informal contacts receive higher or lower wages than those using only formal methods. 
high wages, while others find a negative one. The model I develop in this paper shows that these two findings can coexist. It is important to understand the conditions under which one result dominates the other. I argue that changes in the degree of heterogeneity and changes in the strength of peer influences can have distinct effects. More precisely, in environments with greater cost heterogeneity, a much larger fraction of workers who find jobs through informal search tend to earn higher wages [see Figure (2.2)]. The left-tail becomes fatter, i.e., there is a transfer from Region II to Region I, which leads to a greater fraction of workers with stronger informal connections. Therefore, empirical studies based on samples with greater heterogeneity will tend to find a positive correlation between using informal search and earning high wages. With stronger peer effects, on the other hand, a much larger fraction of workers who find jobs through informal search tend to earn lower wages [see Figure (2.3)]. Greater peer effects does not alter the distribution of workers, but it affects the extent of nonmonotonicities. As Figure (2.3) suggests, stronger peer influences increases the fraction of workers who search informally yet receive lower wages. This is intuitive, because if social forces are more effective in a region or among a group of people, this will lead to more significant referral effects which will manifests itself as a "live-nearby/work-nearby" pattern. I conclude that samples from the regions with large peer effects will tend to yield a negative correlation between using informal search and earning high wages.

It is important to note that, in the first exercise, I shut down peer influences and focus solely on the effect of increased heterogeneity on wages. In this case, changes in the type distribution lead to a change in the wage distribution, but the degree of nonmonotonicities is not altered since $z_{T}$ is unaltered. Varying the dispersion of cost distribution in the presence of peer effects alters not only the wage distribution but the degree of nonmonotonicities [see Figure (2.4)]. This makes the case even stronger: a fatter left tail leads to higher wages in Region I, while the existence of peer effects leads to a slight extension in the degree of nonmonotonicities in Region II. Next section presents the basic model, in which I shut down peer effects. Section 4 introduces peer influences and discusses how the results of Section 3 are altered in this more complicated setting. 


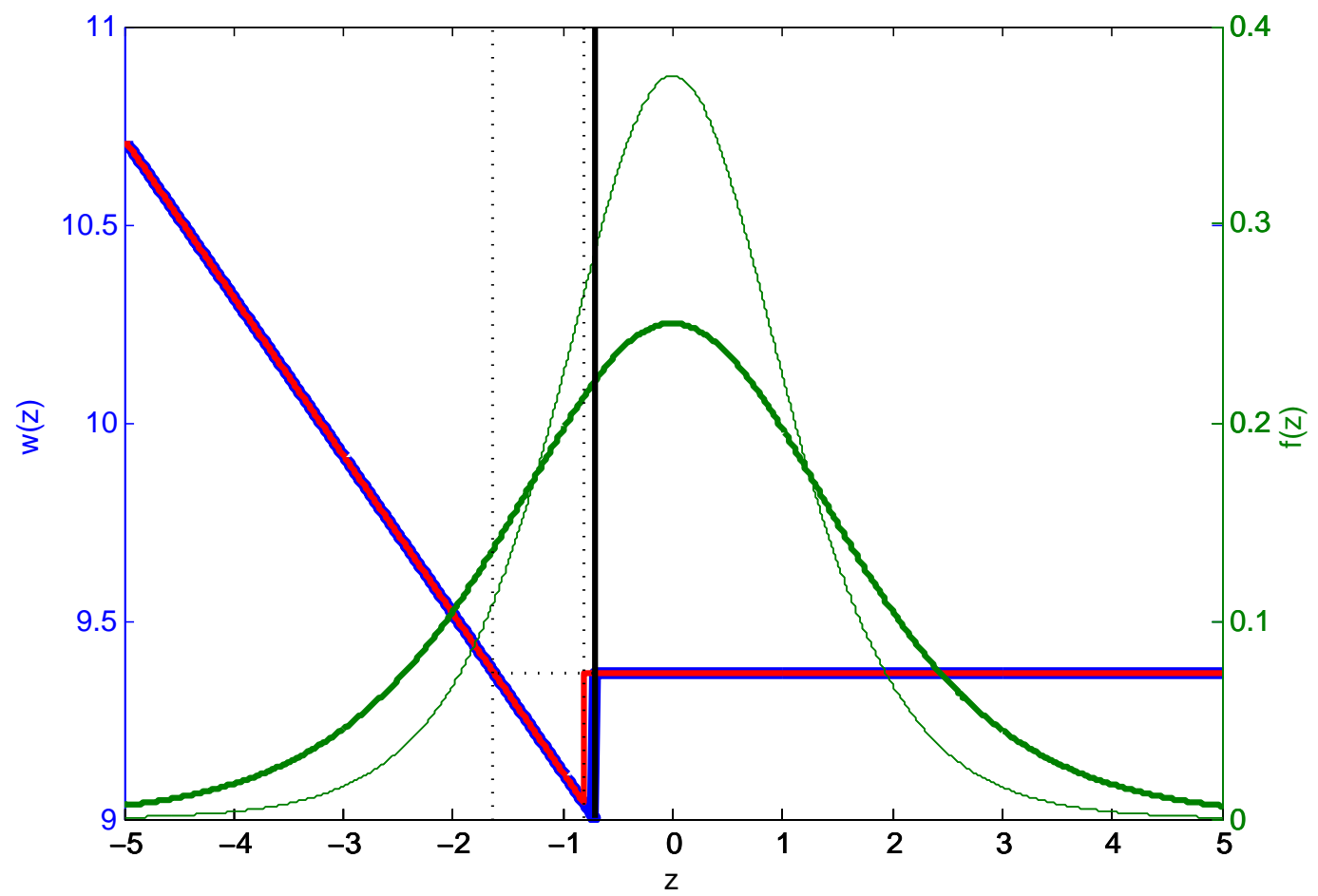

Figure 2.4: InCREASED HETEROGENEITY IN THE PRESENCE OF PEER EFFECTS. This figure displays the effect of increased heterogeneity on wages in the presence of peer influences. The red line corresponds to the wage function with lower heterogeneity and the blue line is the one with greater heterogeneity. As in Figure (2.2), the left-tail becomes fatter and the fraction of high earners among informal job seekers goes up. But the existence of peer effects pushes the threshold type to the right as in Figure (2.3). This finding strengthens the case: greater heterogeneity increases the fraction of high earners and peer effects raise the fraction of low earners among informal job seekers.

\section{Model}

This section introduces an equilibrium job search model in which identical firms post vacancies in segmented markets to attract workers while heterogeneous job seekers engage in costly search. Unemployed workers have two job search options: formal search and informal search. There is no search on the job. Wages are determined via Nash bargaining in each sub-market. Such a setup yields analytically tractable equilibrium distributions of wages and unemployment in the worker population. The details of the model and the solution are presented below. For simplicity, peer effects are ruled out in this section and will be introduced in Section 4 .

It will perhaps be useful to elaborate further on the segmented markets assumption. In heterogeneous-agent search models, there are two options to formulate the matching technology: undirected and directed search. Undirected search formulates the matching function 
in terms of the total number of matches being created and then splits the matches across types. Directed search, on the other hand, assumes that markets are segmented across types and different wages belong to different markets. I adopt the segmented markets assumption for two reasons: $(i)$ for analytical tractability and $(i i)$ with undirected search, the aggregate search intensity needs to be placed into the matching technology, in which case I would lose track of the sources of peer effects (i.e., whether peer influences comes from preferences or the matching technology would be difficult to separate), which is a critical issue in the model. The segmented markets assumption removes this concern and enables me to isolate the effect of peer influences on wages.

The assumptions of directed search and segmented markets are standard in the search literature. There are many breakthrough papers - including but not limited to Burdett, Shi, and Wright (2001), Shi (2002), Shimer (2005), and Decreuse and Zylberberg (2011)—invoking this assumption. One practical reason why directed search in segmented markets is preferred in some papers is that, when heterogeneity among workers and/or firms is assumed, such a setup would yield analytically tractable and well-defined wage distributions at the equilibrium. Besides theoretical arguments, there are also empirical considerations providing some support for segmentation based on the cost of search. It is clearly documented in the literature that the incidence of using informal contacts exhibits considerable variation across race, gender, education, age, experience, industry, and occupation categories. ${ }^{9}$ Moreover, these differences are persistent. In addition to these studies, Holzer (1988), Mortensen and Vishwanath (1994), and Calvo-Armengol and Jackson (2004) argue explicitly that job search costs are heterogeneous across population subgroups, which supports the main assumptions and modeling choices of this paper.

\section{$3.1 \quad$ Worker Heterogeneity}

There is a continuum of workers indexed by $z \in \mathcal{Z}$, where $\mathcal{Z}$ is the support of worker types. Workers are risk neutral and infinitely lived. Each worker seeks to maximize the expected

\footnotetext{
${ }^{9}$ See, for example, Corcoran, Datcher, and Duncan (1980), Datcher (1983), Marsden and Hurlbert (1988), Wegener (1991), Green, Tigges, and Diaz (1999), Falcon and Melendez (2001), and Loury (2006). Topa (2011) present an excellent review of the related literature.
} 
discounted value of labor income, unemployment income, and search effort. Two methods of job search are available for the unemployed worker: she will either rely only on formal methods or invoke also her informal contacts. This is a discrete choice model. The binary discrete variable, $D(z)$, describes the choice of search method for each unemployed worker $z$. $D(z)=0$ if only formal methods are used and $D(z)=1$ if the informal contacts are also invoked by a worker of type $z$.

Formal methods are costless for all workers, i.e., the disutility from using only formal methods is zero for all $z{ }^{10}$ But the cost of invoking informal contacts is not necessarily zero and it differs across workers. It is instructive to interpret this heterogeneous cost as each worker's proximity to an informal network. I assume that the cost of using informal channels is distributed around zero. As a result, some workers have advantages in using informal connections over formal methods. Similarly, some workers have disadvantages in using informal contacts, which tilt their choices toward relying on formal methods only. For analytical simplicity, I let $z$ denote this cost. In other words, workers are indexed by the cost of using informal connections in job search. The distribution of this cost is denoted by the cumulative distribution function $G(z)$, which is centered at zero and assumed to be absolutely continuous with respect to the Lebesgue measure.

After this description, the period utility for type- $z$ workers, $U(z)$, can be written as

$$
U(z)=\left\{\begin{array}{cl}
w(z), & \text { if employed } \\
x-D(z) z, & \text { if unemployed }
\end{array}\right.
$$

where $w(z)$ is the type-specific wage outcome, $x$ is the unemployment income (which is the same for all workers), and $D(z) z$ is the cost of search effort. Parallel to the definiton of the discrete choice structure given above, the cost of job search is zero if the unemployed worker relies only on formal methods, i.e., $D(z)=0$, and it equals $z$ if the unemployed worker invokes also her informal contacts, i.e., $D(z)=1$.

\footnotetext{
${ }^{10}$ Setting the cost of formal search to zero can be considered just as a normalization for the purpose of analytical tractability.
} 


\subsection{Matching Technology and Turnover}

To obtain a clear-cut formulation of the distribution of wages, I assume that firms can direct their search into a specific sub-market - the market for type- $z$ workers. The job matching technology in each sub-market $z$ can therefore be written as

$$
m(z)=m(s(D(z)) u(z), v(z))
$$

where $u(z)$ is the rate of unemployment among type- $z$ workers, $v(z)$ is the vacancy rate in the sub-market $z$, and $s(D(z))$ is the market-specific mean efficiency of search methods. Notice that $s(\cdot)$ is a function of the search method, $D(z)$, preferred by type- $z$ unemployed workers. In other words, it transforms the search effort into effective units of search.

Since all type- $z$ unemployed workers will make the same choice of the search method, $s(D(z))$ will be equal to either $s(0)$ or $s(1)$. A natural implication of this formulation is the inequality $s(1)>s(0)$, which means that relying only on formal methods reduces the efficiency of job search-relative to invoking also the informal contacts. To simplify the calculations, I let $s(0)=\alpha s(1)$, where $0<\alpha<1$.

I assume that the matching technology is of constant returns to scale with positive first-order and negative second-order partial derivatives. The functional form of the matching technology is homogeneous across types. For concreteness, I assume

$$
m(z)=(s(D(z)) u(z))^{\eta} v(z)^{1-\eta}
$$

where $0<\eta<1$. A Poisson process transfers the workers from unemployment to employment with the transition probability for type- $z$ unemployed workers

$$
q(z)=\frac{m(s(D(z)) u(z), v(z))}{s(D(z)) u(z)}=\left(\frac{v(z)}{s(D(z)) u(z)}\right)^{1-\eta} .
$$

Following the conventional notation, I let $\theta(z)=v(z) / s(D(z)) u(z)$ to denote labor market 
tightness for type- $z$ workers, which allows me to write

$$
q(z)=\theta(z)^{1-\eta}
$$

Another Poisson process transfers the jobs from being vacant to filled in sub-market $z$ with the transition probability

$$
q_{f}(z)=\frac{m(s(D(z)) u(z), v(z))}{v(z)}=\left(\frac{s(D(z)) u(z)}{v(z)}\right)^{\eta}
$$

which can, again, be rewritten as

$$
q_{f}(z)=\theta(z)^{-\eta}
$$

Notice that $q(z)$ and $q_{f}(z)$ are related by

$$
q(z)=\theta(z) q_{f}(z)
$$

Let $\gamma$ be the exogenous rate at which job destruction shocks arrive. Standard calculations yield that, at the steady state, the equilibrium unemployment rate for type- $z$ workers is given by

$$
u(z)=\frac{\gamma}{\gamma+\theta(z)^{1-\eta}}
$$

which means that the aggregate rate of unemployment, $u$, in this economy can be calculated with the formula

$$
u=\int_{\mathcal{Z}} \frac{\gamma}{\gamma+\theta(z)^{1-\eta}} d G(z)
$$

The interpretation is the following. There are two distinct values that the tightness parameter can take in each sub-market: $\theta(z)=\theta(z, 1)$ if $D(z)=1$ and $\theta(z)=\theta(z, 0)$ if $D(z)=0$. Clearly, $\theta(z, 1)>\theta(z, 0)$; that is, the rate of unemployment for types who rely only on formal methods is higher than those who invoke also their informal contacts. The aggregate unemployment 
rate is a weighted average of these high and low rates. There exists a threshold type $z_{T}$ that determines this weight. The types $z<z_{T}$ have cost advantage and they choose $D(z)=1$ in the equilibrium, whereas the types $z>z_{T}$ choose $D(z)=0$. It is easy to see that the discrete choice structure allows me to write

$$
u=\int_{-\infty}^{z_{T}} \frac{\gamma}{\gamma+\theta(z, 1)^{1-\eta}} d G(z)+\int_{z_{T}}^{\infty} \frac{\gamma}{\gamma+\theta(z, 0)^{1-\eta}} d G(z)
$$

In other words, those who search only via formal methods (i.e., $z>z_{T}$ ) face a higher unemployment rate, whereas those who invoke also informal methods (i.e., $z<z_{T}$ ) face a lower unemployment rate. The aggregate rate of unemployment is a simple integral over the type horizon. Before describing the solution strategy for determining $z_{T}$, it will perhaps be useful to motivate the threshold crossing behavior that the model exhibits. These type of models are at the heart of discrete choice theory (see, e.g., Heckman (1981)) and have been used extensively in the empirical labor economics literature. In a typical model, an unobserved random variable is defined as a utility difference between the alternative states. This setup captures the essential idea that comparisons between alternative states generate choices. At the threshold, the costs and benefits are equalized and individual's decision problem is solved. The theoretical model in this paper also has a similar flavor. There is a heterogeneity element characterizing the cost of informal search. The agent decides whether to use informal contacts in job search or not by comparing the present discounted value of life-time returns under the two choices. The resulting threshold defines a comparison between formal versus informal search and rationalizes the choice of search methods. Next I describe the solution strategy.

\subsection{Workers' Problem}

Let $r>0$ denote the rate of interest. The present discounted value from unemployment, for a worker of type $z$, is

$$
r V_{u}(z)=x-D(z) z+\theta(z)^{1-\eta}\left(V_{e}(z)-V_{u}(z)\right)
$$


and the present discounted value from employment, for a worker of type $z$, is

$$
r V_{e}(z)=w(z)+\gamma\left(V_{u}(z)-V_{e}(z)\right)
$$

Clearly,

$$
V_{e}(z)=\frac{w(z)+\gamma V_{u}(z)}{r+\gamma}
$$

As a result,

$$
V_{u}(z)=\frac{(r+\gamma)[x-D(z) z]+\theta(z)^{1-\eta} w(z)}{r\left[r+\gamma+\theta(z)^{1-\eta}\right]}
$$

and

$$
V_{e}(z)=\frac{\gamma[x-D(z) z]+\left[r+\theta(z)^{1-\eta}\right] w(z)}{r\left[r+\gamma+\theta(z)^{1-\eta}\right]}
$$

\subsection{Firms' Problem}

Let $W_{o}(z)$ be the present-discounted value of expected profit from an occupied job and $W_{v}(z)$ the present-discounted value of expected profit from a vacant job in market $z$. Let the value of the job's output when it is filled be $p$, where $p>0$ is fixed.

As in the standard search model, I assume that there is free entry, i.e., vacancies are created until they yield zero profit. In other words, all rents from new vacancy creation are exhausted. Once an exogenous shock hits an employment relationship, the job is destoryed. Based on these assumptions, the asset value of an occupied job, $W_{o}$, satisfies the Bellman equation, for a given wage $w(z)$

$$
r W_{o}(z)=p-w(z)-\gamma W_{o}(z) \Rightarrow W_{o}(z)=\frac{p-w(z)}{r+\gamma}
$$

The firm's expected profit from one more job vacancy is

$$
r W_{v}(z)=-p \tau+\theta(z)^{-\eta}\left(W_{o}(z)-W_{v}(z)\right),
$$


where $p \tau>0$ is the fixed hiring cost per time unit. Imposing the well-known equilibrium condition $W_{v}(z)=0$, for all $z$, I get

$$
W_{o}(z)=p \tau \theta(z)^{\eta}
$$

Combining the equations (3.17) and (3.19) gives

$$
p-w(z)-(r+\gamma) p \tau \theta(z)^{\eta}=0
$$

\subsection{Wage Determination}

I derive the wage rate via a Nash bargaining solution; that is, $w(z)$ maximizes the weighted product of the type- $z$ worker's and the firm's net return from the match. The wage rate satisfies

$$
w(z)=\arg \max \left(V_{e}(z)-V_{u}(z)\right)^{\chi}\left(W_{o}(z)-W_{v}(z)\right)^{1-\chi}
$$

where $0 \leq \chi<1$ is a constant and may be interpreted as a relative measure of labor's bargaining strength. Note that $\chi$ has to be strictly smaller than 1 for the firms to have an incentive to open a job. The first-order condition can be expressed as

$$
V_{e}(z)-V_{u}(z)=\chi\left(W_{o}(z)+V_{e}(z)-W_{v}(z)-V_{u}(z)\right)
$$

which, by substituting $V_{e}(z)$ and $W_{o}(z)$ in, can be converted into the following wage equation:

$$
w(z)=r V_{u}(z)+\chi\left(p-r V_{u}(z)\right) .
$$

Using the formula for $V_{u}(z)$, I derive the final wage equation

$$
w(z)=(1-\chi)[x-D(z) z]+\chi p[1+\tau \theta(z)] .
$$


To simplify the notation, I normalize $s(1)=1$, which makes $s(0)=\alpha$, where $0<\alpha<1$. I retain this assumption in the rest of this chapter. Obviously,

$$
w(z)=\left\{\begin{array}{cl}
(1-\chi)[x-z]+\chi p[1+\tau \theta(z, 1)], & \text { if } D(z)=1 \\
(1-\chi) x+\chi p[1+\tau \alpha \theta(z, 1)], & \text { if } D(z)=0
\end{array}\right.
$$

\subsection{Optimal Choice of the Search Method}

The unemployed worker of type $z$ chooses $D(z)=1$ over $D(z)=0$ if $V_{u}(z, 1)>V_{u}(z, 0)$.

Therefore, $\mathbb{P}_{z \mid u}[D(z)=1]=\mathbb{P}_{z \mid u}\left[V_{u}(z, 1)>V_{u}(z, 0)\right]$. The notation $z \mid u$ means that the probability statement is conditioned on being unemployed; that is, I calculate the probability of choosing 1 over choosing 0 among those who are unemployed. Using the formulas derived above,

$$
r V_{u}(z, 1)=\frac{(r+\gamma)[x-z]+\theta(z, 1)^{1-\eta} w(z)}{r+\gamma+\theta(z, 1)^{1-\eta}}
$$

The unemployed worker takes the firms' actions as given when making her own choice of the search method. From (3.20),

$$
w(z)=(1-\chi)[x-z]+\chi p[1+\tau \theta(z, 1)]
$$

when $D(z)=1$. Therefore,

$$
r V_{u}(z, 1)=\frac{\left[r+\gamma+\theta(z, 1)^{1-\eta}(1-\chi)\right](x-z)+\chi p \theta(z, 1)^{1-\eta}[1+\tau \theta(z, 1)]}{r+\gamma+\theta(z, 1)^{1-\eta}} .
$$

Similarly, when $D(z)=0$, the wage equation becomes

$$
w(z)=(1-\chi) x+\chi p[1+\tau \alpha \theta(z, 1)]
$$

which implies that

$$
r V_{u}(z, 0)=\frac{\left[r+\gamma+\alpha^{1-\eta} \theta(z, 1)^{1-\eta}(1-\chi)\right] x+\chi p \alpha^{1-\eta} \theta(z, 1)^{1-\eta}[1+\tau \alpha \theta(z, 1)]}{r+\gamma+\alpha^{1-\eta} \theta(z, 1)^{1-\eta}} .
$$


Following the choice rule, $\mathbb{P}_{z \mid u}[D(z)=1]=\mathbb{P}_{z \mid u}\left[V_{u}(z, 1)>V_{u}(z, 0)\right]$ it is easy to show that

$$
\mathbb{P}_{z \mid u}[D(z)=1]=\mathbb{P}_{z \mid u}\left[z \leq \Psi_{1} x+\Psi_{2} \chi p\right]
$$

where I set

$$
\Psi_{1}=\frac{\chi(r+\gamma) \theta(z, 1)^{1-\eta}\left(\alpha^{1-\eta}-1\right)}{\left[r+\gamma+\alpha^{1-\eta} \theta(z, 1)^{1-\eta}\right] \times\left[r+\gamma+\theta(z, 1)^{1-\eta}(1-\chi)\right]}
$$

and

$$
\Psi_{2}=\frac{\theta(z, 1)^{2-\eta} \tau(r+\gamma)\left[\frac{1-\alpha^{1-\eta}}{\tau \theta(z, 1)}+\left(1-\alpha^{2-\eta}\right)+\frac{\alpha^{1-\eta}(1-\alpha)}{r+\gamma} \theta(z, 1)^{1-\eta}\right]}{\left[r+\gamma+\alpha^{1-\eta} \theta(z, 1)^{1-\eta}\right] \times\left[r+\gamma+\theta(z, 1)^{1-\eta}(1-\chi)\right]}
$$

It is straightforward to prove that $\Psi_{1}<0$ and $\Psi_{2}>0$. The probability statement (3.31) is actually a mean. There is an analogous expression for $\mathbb{P}_{z \mid u}[D(z)=0]$. But it will disappear in calculating the mean since it will be multiplied by zero. Equation (3.31) says that the mean behavioral outcome is determined by two major factors: (1) pecuniary incentives during unemployment, $x$, and (2) the productivity of each filled vacancy multiplied by the worker's share in wage bargaining, $\chi p$.

I perform a quantitative exercise for the purpose of visualizing the predictions of this model. The Current Population Survey (CPS) micro-level data and the Job Openings and Labor Turnover Survey (JOLTS) by the Bureau of Labor Statistics (BLS) aggregate labor market data for the United States covering the 2009-2010 period are used in this exercise. The fixed parameters of the model are chosen to match the 10 percent unemployment rate and 7 percent vacancy rate in the data period. Following Pissarides (2000) and Petrongolo and Pissarides (2001), I set the matching function elasticity parameter $\eta$ to be equal to 0.5. The famous result by Hosios (1990) suggests that the decentralized equilibrium maximizes a wellposed social planner's problem at $\eta=\chi$, where $\chi$ is the bargaining power parameter in wage determination. Based on this result, I set $\chi=0.5$. Since I do not perform a time-series analysis, I use a standard value for the discount rate and set it $r=0.05$ corresponding to an annual discount rate of 0.95 . The parameter $x / p$ roughly represents the replacement rate. 
For the US, it is typically around 0.5. However, as Landais, Michaillat, and Saez (2010) clearly show, the optimal replacement rate goes up to $0.70-0.75$ when unemployment rate is 10 percent-i.e., during recessions. So, we set $x / p=0.75$ since our data is from 2009-2010 period. Finally, the separation probability $(\gamma=0.2)$ and the cost of vacancies $(\tau=0.7)$ are jointly set to match the model's predictions with 7 percent vacancy rate and 10 percent unemployment rate - given the baseline scenario for cost distribution, e.g., $\sigma=1$. These are the institutional parameters and they will be fixed throughout the analysis.

There is also a need to discuss the choice of the distribution of $z$, which is a mean-zero normal distribution. In the baseline analysis, I set the variance at $\sigma=1$, so it collapses into a standard normal distribution. Clearly, the choice of the distribution of search costs is important, because it directly affects the equilibrium wage distribution that the model yields. Thus, in the baseline scenario, the equilibrium wage distribution also resembles a normal distribution. It is well-known that, although the aggregate wage distribution in the US comes from the family of normal distributions, it looks more like a log-normal with a Pareto right tail [see, e.g., Heckman and Sedlacek (1985) and Moscarini (2005)]. Note that $z$ is the distribution of the cost of informal job search. So, obtaining a realistic empirical counterpart for such a distribution is extremely difficult due to data limitations. So, I treat it as an unobserved random variable and assume normality. An alternative way to proceed is to impute the empirical wage distribution into the model and obtain a distribution of the cost of search. However, I conjecture that the qualitative nature of the basic theoretical predictions would be unchanged in such a case, because the empirical distribution would also roughly come from the normal family. The point estimates would change though; but, providing accurate estimates for the unobserved heterogeneity in this model is out of the scope of this paper and would better suit a paper trying to estimate the distribution of unobserved heterogeneity through nonparametric methods.

The main result that this section communicates is the existence of nonmonotonicities in wages, as Figure (2.1) suggests. ${ }^{11}$ Regarding the model mechanics, the reason for these nonmono-

\footnotetext{
${ }^{11}$ The baseline parameters for the cost dispersion $\sigma=1$ (i.e., the variance of the distribution $G$ ) and the social interactions (or
} 
tonicities is the differences among workers in terms of their tolerence to wait for a good offer to arrive. Firms in each sub-market compare wage payments to foregone production and extend a wage offer. The most well-connected type receives the best wage, but the least well-connected one does not receive the lowest wage. Clearly, there exists a thereshold type, below which informal search is chosen and above which workers conduct formal job search. There are some intermediate workers, who earn lower than the formal job seekers. Those intermediate types prefer a lower pay with shorter expected unemployment durations to a higher pay with longer durations of unemployment.

Figure (2.2) demonstrates the effect of increased cost dispersion. Clearly, with greater cost heterogeneity, the fraction of high wage earners among informal job seekers goes up. This suggests that environments with greater cost disperison tend to produce results favoring a positive correlation between informal search and getting high-paying jobs. Notice that the wage structure is unaltered in this exercise, although the wage distribution changes. For the dispersion parameter to have an impact on the wage structure, one needs to introduce peer effects into the model, since in such a setup individuals will care about the distributional features of the worker types.

Next subsection develops a model in which peer effects matter. It provides a discussion of these results, links them to the figures introduced in Section 2, and incorporates peer influences to the model to see how the basic results are altered.

\section{Wage Differentials and Peer Influences}

The model I construct in this section accounts for the possibility that a change in the distributional properties of individual-level heterogeneity may affect the wage distribution. Again, for simplicity, I work with mean-zero normal distributions, but the parameter governing the dispersion of the distribution is no longer restricted to be 1 and it is denoted with $\sigma$. The purpose is to study the effect of a change in $\sigma$ on the distribution of wages and, therefore, on

peer effects) parameter $J=-1$. In Figure (2.2), the cost dispersion is increased to $\sigma=1.5$ (the bold distribution curve) and, in Figure (2.3), the peer effects parameter is changed to $J=-3$ (stronger peer effects denoted with the blue wage schedule). 
the degree of nonmonotonicities. An increase in $\sigma$ can be interpreted as increased inequality. The model in this section is, therefore, capable of answering questions regarding the effect of increased inequality in informal connections on the distribution of wages.

An easy way to let the workers care about the changes in the type distribution is to introduce peer effects into the model. In such a setup, the search method choices of other workers in the reference group will affect the individual-level decision making. A common way to formulate peer effects in this fashion is to use the "preference interactions" framework developed by Schelling $(1971,1973,1978) .{ }^{12}$ This framework inserts a group-level variable into preferences to let the workers respond to social incentives.

Within the context of this model, the fraction of unemployed workers invoking informal contacts in job search affects the cost of search. To reflect this view, I reformulate the period utility as follows:

$$
U(z)=\left\{\begin{array}{cl}
w(z), & \text { if the worker is employed } \\
x-D(z)(J \lambda+z), & \text { otherwise }
\end{array}\right.
$$

where $\lambda \in[0,1]$ is the "endogenous" fraction of unemployed workers choosing $D(z)=1$ and $J<0$ describes the strength of peer influences. More precisely, what others do affects individual-level choices in this formulation; that is, the fact that a lot of unemployed workers choose $D(z)=1$ versus $D(z)=0$ tilts my choices also toward choosing $D(z)=1$. The coefficient $J$ measures how strong the social forces are. Notice that this is a special case of the discrete choice with social interactions framework developed by Brock and Durlauf (2001a) and extended to the job search environment by Tumen (2011, 2012).

I, again, embed this structure into the Mortensen-Pissarides equilibrium search model with segmented markets. There are two points that one needs to pay attention. First, $\lambda$ is an endogenous object. Second, $\lambda$ should be calculated within the reference group (i.e., the pool of unemployed), which is itself endogenous. As in the earlier version, there will be a threshold

\footnotetext{
${ }^{12}$ See Manski (2000) and Brock and Durlauf (2001b) for extensive reviews of the literature. See also Young (1996) for a straightforward conceptual motivation.
} 


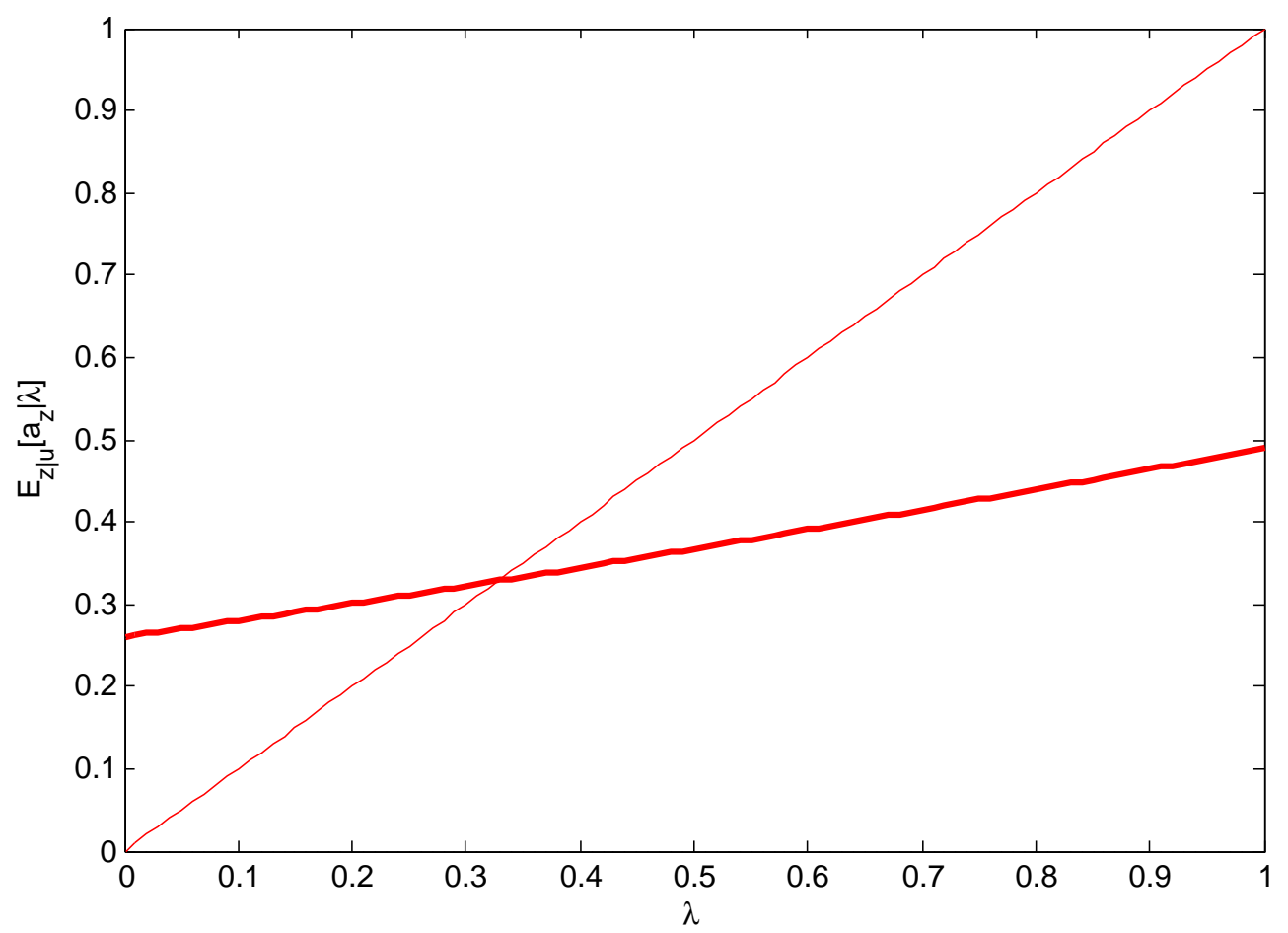

Figure 4.1: Equilibrium solution for $\lambda$. This figure describes the outcome of the fixed-point solution I use in determining $\lambda$. The underlying equation is (4.5). Clearly, in this specific example, around $33 \%$ of workers find jobs through informal contacts at the steady state. This is given by the intersection of the 45 -degree line and the conditional probability function.

type, $z_{T}$, below which everyone uses informal search and above which formal search is preferred.

Thus, $\lambda$ can be calculated as follows:

$$
\lambda=\frac{1}{u} \int_{-\infty}^{z_{T}}[D(z) \mid(D(z)=1) \times u(z)] d G(z),
$$

where $D(z) \mid(D(z)=1) \times u(z)$ is the type-specific fraction of those who choose $D(z)=1 .^{13}$

The solution of this version is the same as that of the previous version except that the wages can now be formulated as:

$$
w(z)=\left\{\begin{array}{cl}
(1-\chi)[x-(J \lambda+z)]+\chi p[1+\tau \theta(z, 1)], & \text { if } D(z)=1 \\
(1-\chi) x+\chi p[1+\tau \alpha \theta(z, 1)], & \text { if } D(z)=0
\end{array}\right.
$$

The only difference is the emergence of $J \lambda$ in the wages of those who choose to invoke informal methods.

\footnotetext{
${ }^{13}$ Remember that all members of a given type $z$ display homogeneous behavior.
} 
The determination of $\lambda$ is the key to the analysis presented in this section. As in Section 3, The unemployed worker of type $z$ chooses $D(z)=1$ if $V_{u}(z, 1)>V_{u}(z, 0)$. The fraction of the unemployed workers who choose to search informally is, therefore,

$$
\begin{aligned}
\mathbb{P}_{z \mid u}[D(Z)=1 \mid \lambda] & =\mathbb{P}_{z \mid u}\left[V_{u}(z, 1)>V_{u}(z, 0) \mid \lambda\right] \\
& =\mathbb{P}_{z \mid u}\left[z \leq \Psi_{1} x+\Psi_{2} \chi p+\Psi_{3} J \lambda\right] .
\end{aligned}
$$

This is the analogue of Equation (3.31). The only difference is that the fraction of unemployed workers who choose to search informally, $\lambda$, also affects the choice of the search method. Self consistency requires that

$$
\lambda=\mathbb{P}_{z \mid u}\left[z \leq \Psi_{1} x+\Psi_{2} \chi p+\Psi_{3} J \lambda\right]
$$

which can be solved for $\lambda$ using a standard fixed-point argument. The left-hand side is a 45-degree line and the right-hand side is a cumulative distribution function (or, equivalently, a conditional expectation function). Figure (4.1) visualizes the solution of this fixed-point problem for the parameter values provided in Section 3. Notice that the conditional expectation is a function of the dispersion of worker types, $\sigma$. After pinning down $\lambda$, one can vary $\sigma$ and analyze the effect of a change in the distribution properties of the labor force on the wage distribution, and, therefore, on the differentials between the wages paid by the jobs found through informal versus formal search.

Figure (2.3) displays the results of playing with $J$. More precisely, $J$ is changed to -3 from -1. Obviously, stronger peer effects operate at the low end of the earnings for the informal job searchers. This suggests that peer effects are most effective for low-skill workers. Thus, with stronger peer effects, the wages paid to informal job searchers tend to be lower than the wages paid to formal searchers. Now suppose that the dispersion of the cost distribution goes up in the presence of peer influences [see Figure (2.4)]. Similar to the predictions of the model with no peer effects, increased cost dispersion raises the fraction of high earners. But the existence of peer effects raises the fraction of low earners too. This result makes the case even stronger. 
The interpretation is as follows. Think of a neighborhood most of the residents of which work in a large nearby factory. This live-nearby/work-nearby patterns are usually associated with blue-collar occupations and poor neighborhoods. If the norm is to search informally, then $J$ will take a large negative value implying strong peer influences in the choice of job search methods. In other words, peer influences will reduce the cost of informal search and induce the workers rely mostly on referrals in job search.

Bringing the results of Sections 3 and 4 together, I conclude that - for those who choose to search informally - heterogeneity operates among high earners, whereas peer effects operate among low earners. The main result is that in environments with greater cost heterogeneity informal search tend to yield higher wages than formal search, while in environments with strong peer effects the opposite statement tends to be true.

\section{Concluding Remarks}

There is a divide in the empirical literature investigating the correlations between earnings and informal networks: some papers find positive correlation between getting help from informal contacts in job search and higher wages, while others find a negative correlation. This paper proposes a unifying theoretical model constructed for the purpose of comparing the wage outcomes associated with informal versus formal job search channels in a general equilibrium setup. The model is a version of the canonical Mortensen-Pissarides equilibrium search model with segmented markets, worker heterogeneity, and peer influences in job search. Wages are determined via Nash bargaining in segmented markets and a wage distribution arises in the equilibrium. Whether a worker has strong informal connections or not enters the Nash bargain and plays a critical role in wage determination.

More specifically, the paper features four main results. First, the equilibrium distribution of wages exhibit nonmonotonicities. These nonmonotonicities communicate the idea that the jobs found through informal methods pay for some groups higher and for some others lower wages than the jobs found through formal methods. This finding reconciles the seemingly 
conflicting empirical findings about the effect of informal search on wages. Second, as the worker types become more dispersed (i.e., as the inequality in terms of low-cost access to informal networks goes up), the correlation between using informal job search and getting high-paying jobs tends to be positive. Third, as peer effects become stronger, the correlation tends to be negative. As a result, the model disentangles the forces operate at the higher end versus the lower end of the wage distribution.

The model's predictions communicate the lesson that the extent of unobserved heterogeneity and strength of peer effects determine the correlation between earnings an informal contacts. This result can be translated into the following criticism: the empirical papers in the literature fail to successfully control for unobserved heterogeneity and peer effects in their estimates. This conclusion informs the empirical research in the sense that identification of the true correlation between job contact methods and wage offers requires a careful assessment of the unobserved heterogeneity and peer influences in the relevant sample. 


\section{References}

Addison, J. T. And P. Portugal (2002): "Job Search Methods and Outcomes," Oxford Economic Papers, 54, 505-533.

Antoninis, M. (2006): "The Wage Effects from the Use of Personal Contacts as Hiring Channels," Journal of Economic Behavior \&5 Organization, 59, 133-146.

Bayer, P., S. L. Ross, And G. Topa (2008): "Place of Work and Place of Residence: Informal Hiring Networks and Labor Market Outcomes," Journal of Political Economy, $116,1150-1196$.

Beggs, J. And J. Hurlbert (1997): "The Social Context of Mens and Womens Job Search Ties: Membership in Voluntary Organizations, Social Resources, and Job Search Outcomes," Sociological Perspectives, 40, 601-622.

Bentolila, S., C. Michelacci, And J. Suarez (2010): "Social Contacts and Occupational Choice," Economica, 77, 20-45.

Bewley, T. (1999): Why Wages Don't Fall During a Recession, Cambridge, MA: Harvard University Press.

BÖheim, R. And M. P. TAYlor (2002): "Job Search Methods, Intensity and Success in Britain in the 1990s," Unpublished manuscript, Johannes Kepler University.

Bridges, W. And W. Villemez (1986): "Informal Hiring and Income in the Labor Market," American Sociological Review, 51, 574-582.

Brock, W. A. And S. N. Durlauf (2001a): "Discrete Choice with Social Interactions," Review of Economic Studies, 68, 235-260.

(2001b): "Interactions-Based Models," in Handbook of Econometrics, ed. by J. J. Heckman and E. E. Leamer, New York: Elsevier, vol. 5, 3463-3568.

Burdett, K., S. Shi, And R. Wright (2001): "Pricing and Matching with Frictions," Journal of Political Economy, 109, 1060-1085. 
Calvo-Armengol, A. And M. O. Jackson (2004): "The Effects of Social Networks on Employment and Inequality," American Economic Review, 94, 426-454.

Corcoran, M., L. Datcher, And G. Duncan (1980): "Information and Influence Networks in Labor Markets," in Five Thousand American Families: Patterns of Economic Progress, ed. by G. Duncan and J. Morgan, Ann Arbor, MI: Institute for Social Research, $71-114$.

DAtcher, L. (1983): "The Impact of Informal Networks on Quit Behavior," Review of Economics and Statistics, 65, 491-495.

Decreuse, B. And A. Zylberberg (2011): "Search Intensity, Directed Search, and the Wage Distribution," Journal of the European Economic Association, 9, 1168-1186.

Elliot, J. (1999): "Social Isolation and Labor Market Isolation: Network and Neighborhood Effects on Less-Educated Urban Workers," Sociological Quarterly, 40, 199-216.

Falcon, L. And E. Melendez (2001): "Racial and Ethnic Differences in Job Searching in Urban Areas," in Urban Inequality: Evidence from Four Cities, ed. by A. O'Connor, L. Bobo, and C. Tilly, New York, NY: Russell Sage Foundation, 341-371.

Fontaine, F. (2008): "Why Are Similar Workers Paid Differently? The Role of Social Networks," Journal of Economic Dynamics and Control, 32, 3960-3977.

Granovetter, M. S. (1995): Getting a Job: A Study of Contacts and Careers, Chicago, IL: University of Chicago Press.

Green, G. P., L. M. Tigges, and D. Diaz (1999): "Racial and Ethnic Differences in Job-Search Strategies in Atlanta, Boston, and Los Angeles," Social Science Quarterly, 80, $263-278$.

Heath, A. (1999): "Job-Search Methods, Neighbourhood Effects and the Youth Labour Market," Research Discussion Paper Series, RDP1999-07, Reserve Bank of Australia.

Heckman, J. J. (1981): "Statistical Models for Discrete Panel Data," in Structural Analysis of Discrete Data, ed. by C. F. Manski and D. L. McFadden, Cambridge, MA: MIT Press. 
Heckman, J. J. And G. SedlaceK (1985): "Heterogeneity, Aggregation, and Market Wage Functions: An Empirical Model of Self-Selection in the Labor Market," Journal of Political Economy, 93, 1077-1125.

Holzer, H. J. (1987): "Job Search by Employed and Unemployed Youths," Industrial and Labor Relations Review, 40, 601-611.

(1988): "Search Methods Used by Unemployed Youth," Journal of Labor Economics, $6,1-20$.

Hosios, A. J. (1990): "On the Efficiency of Matching and Related Models of Search and Unemployment," Review of Economic Studies, 57, 279-298.

IoAnNides, Y. M. AND L. D. Loury (2004): "Job Information Networks, Neighborhood Effects, and Inequality," Journal of Economic Literature, 42, 1056-1093.

Landais, C., P. Michaillat, and E. Saez (2010): "Optimal Unemployment Insurance over the Business Cycle," NBER Working Paper \#16526.

Loury, L. D. (2006): "Some Contacts Are More Equal than Others: Informal Networks, Job Tenure, and Wages," Journal of Labor Economics, 24, 299-318.

Manski, C. F. (2000): "Economic Analysis of Social Interactions," Journal of Economic Perspectives, 14, 115-136.

Marmaros, D. And B. Sacerdote (2002): "Peer and Social Networks in Job Search," European Economic Review, 46, 870-879.

Marsden, P. V. and K. E. Campbell (1990): "Recruitment and Selection Processes: The Organizational Side of Job Searches," in Social Mobility and Social Structure, ed. by R. L. Breiger, New York, NY: Cambridge University Press.

Marsden, P. V. And E. Gorman (2001): "Social Network, Job Changes, and Recruitment," in Sourcebook of Labor Markets: Evolving Structures and Processes, ed. by I. Berg and A. Kalleberg, New York, NY: Plenum. 
Marsden, P. V. And J. Hurlbert (1988): "Social Resources and Mobility Outcomes: A Replication and Extension," Social Forces, 66, 1038-1059.

Mencken, F. C. And I. Winfield (2000): "Job Search and Sex Segregation: Does Sex of Social Contact Matter?" Sex Roles, 42, 847-864.

Montgomery, J. D. (1991): "Social Networks and Labor Market Outcomes: Toward an Economic Analysis," American Economic Review, 81, 1408-1418.

Mortensen, D. T. And T. Vishwanath (1994): "Personal Contacts and Earnings: It Is Who You Know!" Labour Economics, 1, 187-201.

Moscarini, G. (2005): “Job Matching and the Wage Distribution," Econometrica, 73, 481516.

Pellizzari, M. (2010): "Do Friends and Relatives Really Help in Getting a Good Job?" Industrial and Labor Relations Review, 63, 494-510.

Petrongolo, B. And C. A. Pissarides (2001): "Looking into the Black Box: A Survey of the Matching Function," Journal of Economic Literature, 39, 390-431.

Pissarides, C. A. (2000): Equilibrium Unemployment Theory, Cambridge, MA: MIT Press.

Pistaferri, L. (1999): "Informal Networks in the Italian Labor Market," Giornale degli Economisti, 58, 355-375.

ReEs, A. (1966): "Information Networks in Labor Markets," American Economic Review, $56,559-566$.

Rosenbaum, J. E., S. Deluca, S. R. Miller, and K. Roy (1999): "Pathways into Work: Short- and Long-Term Effects of Personal and Institutional Ties," Sociology of Education, $72,179-196$.

SAloner, G. (1985): "Old Boy Networks as Screening Mechanisms," Journal of Labor Economics, 3, 255-267. 
Schelling, T. C. (1971): "Dynamic Models of Segregation," Journal of Mathematical Psychology, 1, 143-186.

(1973): "Hockey Helmets, Concealed Weapons, and Daylight Savings: A Study of Binary Choices with Externalities," Journal of Conflict Resolution, 17, 381-428.

— (1978): Micromotives and Macrobehavior, New York, NY: W. W. Norton.

SHI, S. (2002): "A Directed Search Model of Inequality with Heterogeneous Skills and SkillBiased Technology," Review of Economic Studies, 69, 467-491.

Shimer, R. (2005): "The Assignment of Workers to Jobs in an Economy with Coordination Frictions," Journal of Political Economy, 113, 996-1025.

Simon, C. J. And J. T. WARner (1992): "Matchmaker, Matchmaker: The Effect of Old Boy Networks on Job Match Quality, Earnings and Tenure," Journal of Labor Economics, $10,306-330$.

Smith, S. (2000): "Mobilizing Social Resources: Race, Ethnic, and Gender Differences in Social Capital and Persisting Wage Inequalities," Sociological Quarterly, 41, 509-537.

TopA, G. (2011): "Labor Markets and Referrals," in Handbook of Social Economics, ed. by J. Benhabib and A. Bisin, New York, NY: Elsevier, vol. 1, chap. 22, 1193-1221.

Tumen, S. (2011): "Essays on Endogenous Social Effects," Ph.D. thesis, University of Chicago.

(2012): "Social Interactions and Unemployment Fluctuations," Unpublished manuscript, University of Chicago.

Wegener, B. (1991): "Job Mobility and Social Ties: Social Resources, Prior Job, and Status Attainment," American Sociological Review, 56, 60-71.

Young, P. (1996): "The Economics of Convention," Journal of Economic Perspectives, 10, $105-122$. 
Zaharieva, A. (2012): "Double Matching: Social Contacts in a Labour Market with Onthe-Job Search," Unpublished manuscript, Bielefeld University.

(2013): "Social Welfare and Wage Inequality in Search Equilibrium with Personal Contacts," Labour Economics, 23, 107-121. 